\title{
Donor Support for Community Health Financing: Options and Opportunities for Sub-Saharan African Communities
}

\author{
Ejughemre Ufuoma John* \\ Department of Community Medicine, Delta State University Teaching Hospital, Oghara, Delta State \\ *Corresponding author: ufuoma83@gmail.com
}

Received May 30, 2013; Revised June 12, 2013; Accepted June 15, 2013

\begin{abstract}
International developmental support in sub-Saharan Africa has been quite remarkable in helping to address a number of challenges bedevilling healthcare delivery in the region. However, these humanitarian actions have just being a part of the developmental picture, as there is the need for more robust activities by these actors to support local policies particularly in the area of community health financing. As it were, this will involve building and supporting workable and sustainable 'pre-payment' schemes, supporting national governments to obtain the necessary information through more robust methods in data collection and in local research on health care financing in order to provide accurate information to inform policy on both the costs and benefits of alternatives of community health financing. Furthermore, as these now come to bear, donor support for community health financing will not only improve on access to health care delivery amongst the poorest of the poor in sub-Saharan Africa but will create a platform for these donor recipient countries to be self-sufficient and self reliant, and should these agencies cease to continue or run out of funding the consequences for the region will not be dire.
\end{abstract}

Keywords: donor support, sub-Saharan Africa, community health financing, pre-payment schemes

\section{Introduction}

Donor developmental assistance in sub-Saharan Africa has being fairly remarkable with funding to combat major health problems reaching unprecedented levels and improvements on a number of fronts [1]. These humanitarian actions have had some remarkable strides in health systems performance in the region by improving local health care infrastructure, management, communications, laboratories, information systems, and human resources as well as contributing to standardization of services and strengthening of monitoring and surveillance systems in health systems [2,3,4,5]. However, despite the perennial injections of sky rocketing sums of donor funds; the high disease burden in the region bothers on the poor state of health of many of its citizens which is further exacerbated by the harrowing conditions of health care delivery and the poor financing for health services in many of its rural communities [6] On the average, most of the resources for financing health care services in the region come from out of pocket sources or user fees (about 52\%) [7,8,9]; however, evidence has shown that governmental health care expenditure in sub-Saharan Africa is grossly behind the set target by the World Health Organization (WHO) [10]. Only six countries in the WHO African region spend at least $15 \%$ of their national budget on health: Rwanda, $18.8 \%$, Botswana, $17.8 \%$, Niger, 17.8\%, Malawi, 17.1\%, Zambia, $16.4 \%$ and Burkina Faso, $15.8 \%$. Furthermore, thirty-two out of fifty-three African
Union member states spend less than the US $\$ 40$ recommended per person by the WHO, with only eleven of these investing about US\$5 or less per capita [10]. The import being that while billions of dollars of donor support continues to be poured into the region to narrow the divide created by poor governmental budgetary allocation for health and out-of pocket spending, the divide will continue to pervade health systems in the region with poor health outcomes to show case particularly in many of its rural communities. Of such will be the persistence of high child and maternal mortality rates, steady increase in non-communicable diseases/states such as diabetes, hypertension, stroke and road traffic accidents as a result of rising costs for treatments.

While these challenges continues to bother on health care delivery in sub-Saharan Africa, the situation now calls for a rapt attention to rapidly ameliorate the poor health care financing particularly in its rural communities. This is because the regressive burden of out of pocket payments for health services' pervading many subSaharan African communities is now a critical challenge facing its health policy makers. The issue now is how to decrease this burden by expanding available option(s) so as to reduce the spectre of catastrophic health care expenditures by most of its citizens. Of such may be the channeling of international developmental funds for health care assistance to 'build' and 'support' workable and sustainable 'pre-payment' schemes besides other supports for community health financing that could be benefited particularly for low income communities in sub-Saharan African. 


\section{The Situation Amidst the Prevailing Options}

The poor state of the health care delivery in subSaharan African countries have been traced to several factors especially the gross under funding of their health sectors [10,11]. These countries now rely on a disaggregated mixture of health financing options including; government budgetary allocation, private outof-pocket spending, health insurance and external funding (donor support) to finance health care. Against this backdrop, health policy makers in the region are now faced with competing alternatives for health care financing. To this end, the choice(s) of health financing should mobilize resources for health care and provide sustainable financial protection [12] Choices should therefore ensure that people are not denied access to health care services because they cannot afford it, as this is the cornerstone of modern health financing systems in many countries [12,13].

As the case for making choices for health financing now comes to bear, it is critical to further look into the competing alternatives for health care financing while attempting to make suggestions for the use of donor funds as a pedestal to drive health financing in sub-Saharan African communities.

\subsection{Government Budgetary Allocation}

In the recent past decade there have been calls for scaling up of government allocation to health care. Of such was the Abuja declaration by African Heads of State and Government in 2001 to allocate at least $15 \%$ of their countries' annual budgets to the health sector [14] This decision took into cognisance that Africa has the highest disease burden compared with other regions; yet it has the lowest per capita spending on health (amid escalating health services costs) worldwide [15] Despite the pledge by heads of government in the region to increase local investment in health, what is obtainable is that most governments in the region are not adequately funding health care delivery [10] In 2007, twenty-seven (51\%) out the fifty-three countries spent less than US\$50 per person on health and by 2010 the situation had barely changed $[10,16]$. These accounted for only $30 \%$ of health financing in the region [16]. More so, evidence from reports shows that by 2010; in the WHO African region only six countries allocated at least $15 \%$ of their annual budget for health care delivery [10]. Reasons often given by governments are increasing competing demands for lean national budgets amidst the low gross domestic product and slow overall economic growth.

Furthermore, besides the critical shortage in direct budgetary allocation to health care delivery in a region where about $60 \%$ of its populace live in rural communities, the current situation is also characterized by inefficient use of existing resources, weak mechanisms for coordinating and implementing of national health policies and strategic plans, as well as the lack of effective social protective mechanisms to ensure equitable access to health care [15].

For instance, evidence from a study shows that overall, Zambian hospitals were operating at $67 \%$ level of efficiency, with only $40 \%$ of hospitals (i.e eleven of the thirty hospitals) being allocatively and technically efficient in relative terms [17]. It revealed that sizes of health centres were a major source of inefficiency in resource utilization as these health facilities were too large for the population they served. Another study in Ghana showed that $78 \%$ of health centres were using resources that they did not actually need and attributed it as technically inefficient [18]. Additionally; there are several instances, as shown from surveys in Uganda revealing that weak mechanisms for coordinating supply management often results in increased leakage rate for drugs which was estimated at $73 \%$ across 10 public health facilities where high demand drugs, such as those to treat malaria being the least available to patients because health workers and the Health Unit Management Committee members, the entities meant to provide local oversight, expropriated them [19]. Issues such as these and more occurs across sub-Saharan Africa.

Additionally, while most governments in the region have not shown commitments towards increasing investments in health care in order to scale up health care delivery, the question is; will countries be able to address the already existing health care delivery gap between now and 2015?. Estimates by the Health for Harmonization for Africa showed that it will take investing an additional average of US\$21 to US\$36 per capita per year over five years (i.e between 2011-2015) to save 3.1 million lives in the region (of which $90 \%$ would be among mothers and children), prevent between 3.8 million and 5.1 million children from stunting, build an additional 58,268 to 77,100 health facilities, and produce an additional 2 million to 2.8 million health workers [15,20,21]. It could then be asserted that most of these governments will find it difficult to realize this further ambitions if at all.

\subsection{Out of Pocket Sources}

The situation in the region shows that many of its communities are low income with many of its people living below US \$2 per day [22]. This coupled with the rapid population growth alongside inadequate economic planning, poses difficulties to health care services delivery and affordability. These have now created a situation where the major alternative for health financing is the out of pocket expenditures. It now accounts for over $50 \%$ of all contributions to payments for health services especially in rural communities [23]. Out of pocket payment for health care services; a widely used strategy to supplement governmental resources in sub-Saharan Africa, further aggravates the situation. As it were, it has been 'catastrophic' in the sense that it aggravates poverty by crowding-out other essential consumption items such as food, clothing and housing, leaving its negative toll on the economy [24,25,26]. For instance, in Nigeria, while there have been the scaling up of primary health care through upgrade of existing facilities and building of health centres where they were not available, the utilization of these have still not been encouraging. Healthcare services in these facilities in many parts of the country have remained low with slight improvement in some areas in recent years [27]. Several studies have shown that community's perceptions of poor quality, inadequacy of available services and payment of services are some of the major reasons responsible for low use of health services [28,29]. Furthermore, other possible challenge with direct 
payments is that it could support corrupt practices in health service delivery as there are reports of wrong or informal charging of clientele at the point of service delivery [19]. To this end there is a large body of literature that supports the reduction and if possible the elimination of direct payments -out of pocket expenditure- as the main stay in paying for health services in developing countries while promoting viable alternatives such as community health financing [12,30,31,32].

\subsection{Health Insurance and Community Health Financing}

While direct government budgetary allocation and private out-of-pocket spending do come to bear, health financing through insurance appears to be a viable alternative to easing the existing burden of payments for health services in the region. It is now known that health financing through social insurance to a very large extent can reduce financial barriers to health care access and provide protection for individuals and families against the risk of unpredictable health care expenditures [33,34]. Pre-payment via health insurance is seen as one of the viable options that are available to broaden sources of health care financing and hence reduce the dependence and pressure on government budget in developing countries [12,35]. However, the challenge facing the implementation of most health insurance models in the region is that most of its citizens are largely rural and many of whom work in the informal sectors. These schemes (social and private health insurance) more than often tends to exclude millions of sub-Saharan Africans [36]. Additionally, the inefficiency in premium collections, limited coverage, bureaucratic obstacles, tedious claiming processes and a high transaction cost that is sometimes fuelled by fraud and abuse have bedeviled such schemes in the region [35]. To this end, literary evidence from reports in South Africa has it that despite the projections for the National health insurance (NHI) corruption and sharp practices as it were in the health sector will undoubtedly also hinder the effective implementation of NHI [37]. Another instance has it that the Nigerian health insurance experience reveals that policy regulators chose a staggered approach to health insurance scheme implementation were it was limited to only a small proportion of the citizenry who had difficulty in accessing and utilization of services these insurance packages were meant for [38].

These challenges have now necessitated the implementation of community financing in sub-Saharan African communities [39,40]. As it were, community financing involves a number of arrangements which could be: micro-insurance, community health funds, mutual health organizations, rural health insurance, revolving drug funds, and community involvement in user-fee management [41]. To this end, it operates through a mechanism whereby households in a community, finance or co-finance the current and or capital costs associated with a given set of health services [42]. At the same time enrolees (households) are expected to gain participation in the management of the financing scheme and the organization of health services [42]. This now comes to bear as a viable and sustainable option to address the perennial regressive burden of out-of pocket expenditure for health services, more so the poor financing of health care delivery in a region that is faced with burgeoning health care delivery challenges. Leveraging on some of its arrangements (such as rural health insurance and community involvement in user-fee management) will provide vistas of opportunities for which international donors can draw from to provide, build and support workable and sustainable health financing schemes particularly for millions in the rural communities in subSaharan Africa, as efforts are geared towards achieving the millennium development goals.

\section{Opportunities through Donor Support}

While the options for financing of health care delivery with a view to choosing the optimal policy mix continues to bother health policy makers in sub-Saharan Africa and beyound, the channeling of international donor developmental assistance to support workable and sustainable pre-payment schemes in sub-Saharan Africa is now of critical consideration. This takes into cognizance that financing through pre-payment schemes are generally recognized to be powerful methods to achieve universal coverage with adequate financial protection for all against healthcare costs [42]. As it were, this system intends to respond to the goal of equity in health financing, in that beneficiaries are asked to pay according to their means (as well as supporting their risk purchasing power) while guaranteeing them the right to health services according to need. As many sub-Saharan African communities are low income and do face difficulties in achieving universal financial protection the importance of this cannot be overestimated [43].

However, the challenges facing most community health financing schemes are resource mobilization and financial risk protection $[44,45]$. It is of cardinal interest that efforts geared towards bolstering community health financing in sub-Saharan Africa takes these into cognizance. For instance, there have been reports of insufficient resource mobilization and poor risk protection by such financing arrangements in low income communities in the recent past $^{12}$ this then necessitates a new leaf to address these issues. It is here that donors and international organizations can play instrumental roles. Of these will include: (i.) Direct injection of funds into such systems to reduce the challenges of resource mobilization and financial risk protection (ii.) Supporting national governments in obtaining the necessary information and in local research on health care financing options, particularly community financing.

\subsection{Resource Mobilization and Financial Risk Protection:}

Recognizing that resource mobilization and financial risk protection are targets in community health financing through pre-payment schemes, the population covered is therefore an indicator of the general attractiveness of the scheme [42]. While membership is a crucial feature, it is equally important that sufficient revenues are collected. The higher the volume of prepayment contributions, the more one can avoid the financial consequences of treatment costs and secure access to care when it is needed. 
Moreover, the situation shows that the region is characterised mainly by low income earners [22] and its communities do provide the right population clusters (households) to benefit from any such. Although resource mobilization may seem to be a herculean task as it were in rural communities in the region, donor funds could come in crucial to leverage, accelerate resource mobilization and secure risk pooling. For instance, anecdotal reports and evidence findings from India provides examples were funds are collected from members of the community into a large pooled contributory fund scheme ( the Yeshasvini cooperative healthcare scheme) [46]. Its operational mechanism has it that within the first two years, members pay as low US\$1.08 for each person in the scheme. By the third year, the premium increases to only US\$2.20 and subsequently increased in the fifth year to include a marketing incentive of approximately US20cents for third parties (co-operative societies) [46]. While premiums are being mobilized from the community, donor funds could be used as a leverage to provide subsidy and protect risk of pooled funds thus increasing the level of possible benefits to the members. As it were, it would also address the issues of moral hazards that may arise as a result of the burden from unexpected health care expenditures by enrolees in the community as well as adverse selection phenomenon and broadening the scope of benefits provided to its members $[47,48]$. Furthermore, in this situation, relatively poor areas with high health risks will be able to set contributions at an affordable level, in view of subsidies/supports received via donor findings [42]. There is already substantial evidence from studies of low income earners and contributory pooled funds with subsidies for health in the region as is the case of the Bwamanda Scheme in the Democratic Republic of Congo and in the Nkoranza Scheme in Ghana where the enrolment was high $[42,48]$. These could serve as exemplary templates that could drive donor support for community health financing in sub-Saharan Africa.

\subsection{Supporting Governments in Obtaining Information and Research on Health Care Financing Options:}

Besides the direct injections of donor funds to support pre-payment schemes, donor international organizations will be instrumental to supporting national governments in the region in obtaining the necessary information on health care financing options. This will require more robust methods in data collection in sub-Saharan African countries with a view to generating information on both the costs and benefits of alternatives to community health financing and linking the substantive evidence generated to inform policy [42]. Evidence has shown that adequately funded programmes cannot be achieved if health care resources are not used wisely through decisions and actions from evidenced-informed policies [49]. As it were, a good example is the case of drug treatment for uncomplicated falciparum malaria in sub-Saharan Africa. While expert findings by the World Health Organization (WHO) recommends artemisinin-based combination therapies (ACTs) as first-line treatment for this disease based on high-quality evidence [50], health policymakers in the African region who were willing to support a national adoption and roll-out of ACTs found out a wealth of evidence that were conducted locally to support their actions and inactions [51]. More so, there are reports that well designed health care programmes in the region and other developing countries have failed to meet their objectives when they were not well-informed by research evidence locally [52]. This should drive international donors in supporting continued research in the area of health financing, including community financing. A critical example which will come to bear in the region will be the continued implementation of the guidelines on conducting case studies on micro-health insurance of the International Labour Organization STEP programme [53]. Furthermore, while there are substantive reports of successes in community financing globally, the regular systematic assessment and evaluation of these schemes by these humanitarian actors will be of critical interest if sustainability is anything to go by in this region.

\section{Conclusion}

While poor health care financing continues to remain a challenge pervading health systems and health care delivery in many sub-Saharan African rural communities, international developmental assistance to the region has been quite remarkable in helping to address a number of challenges bedevilling healthcare delivery in the region. However, these humanitarian actions has being just a part of the developmental picture, as there is the need for more robust activities by these actors to support local policies in order to reduce over reliance on donor funding for health. The import being that while billions of dollars of donor support continues to be poured into the region to narrow the divide created by poor governmental budgetary allocation for health and out-of pocket spending, the divide will continue to pervade health systems in the region with poor health outcomes to show case particularly in many of its rural communities. Of such will be the persistence of high child and maternal mortality rates, steady increase in non-communicable diseases/states such as diabetes, hypertension, stroke and road traffic accidents as a result of rising costs for treatments.

To this end, this will involve building and supporting workable and sustainable pre-payment schemes and supporting national governments in obtaining the necessary information through improved data collection and continued research on health care financing options, particularly community health financing in the region. As these now come to bear, they will not only further strengthen health system and improve on access to health care delivery amongst the poorest of the poor in subSaharan Africa but will create a platform for these donor recipient countries to be self-sufficient and self reliant, and should these agencies cease to continue or run out of funding the consequences for the region will not be dire.

\section{Evidence for Review}

Literature reviews are summaries of research evidence that address research questions or issues by using explicit methods to identify, select, and critically appraise relevant research studies or documents, and to collect and analyse data from the studies that are included for the review. To 
this end, this review involved a broad search of literatures on international developmental assistance and health financing in sub-Saharan Africa with interests on direct government budgetary allocation and prepayment schemes. By using broad criteria the author made the review as inclusive as possible and online search engines and databases including PUBMED, Google Scholar and EMBASE were searched as well as grey literature and hand searches were done. However, due to paucity of research evidence on donor support for community health financing in the region the evidence was thus limited and this calls for further research in this regards.

\section{Authors' Statement}

This paper clearly expresses the views of the author as there are no competing interests (financial or personal). For enquires on the views of this document please contact the author.

\section{Acknowledgements}

I give all gratitude to God Almighty for his inspiration and the suggestions of the anonymous peer reviewers.

\section{References}

[1] Duber H.C, Coates T.J, Szekeras G, Kaji A.H and Roger J Lewis. Is there an association between PEPFAR funding and improvement in national health indicators in Africa? A retrospective study. Journal of the International AIDS Society 2010,13:21;1.

[2] Musango L. Impact of HIV Projects on Health Systems in Rwanda. 2007, Kigali, Rwanda.

[3] Price JE, Leslie JA, Welsh M, Binagwaho A. Integrating HIV clinical services into primary health care in Rwanda: a measure of quantitative effects. AIDS Care, 2009, 21: 608-614.

[4] Yu D, Souteyrand Y, Banda MA, Kaufman J, Perriens JH. Investment in HIV/AIDS programs: does it help strengthen health systems in developing countries? Global Health, 2008, 4: 8.

[5] Delph E. Global Vertical Programmes. The Future of Aid or a Quick Fix? Quezon City, the Philippines: EURODAD, 2008.

[6] Bryan L., Conway M., Keesmat T., McKeena S., Richardson, B. A practical guide to Health System Strengthening in sub-Saharan Africa. Health International, 2009, pp1-3.

[7] Crisp, N. Turning the world upside down - the search for global health in the 21st century. Royal Society of Medicine Press 2010; 186-188.

[8] Meessen B, Zhenzhong Z, van Damme W et al. Editorial: Iatrogenic poverty. Tropical Medicine and International Health. 2003; 8: 581-4.

[9] Frenk J, Gonzalez-Pier E, Gomez-Dantes O, Lezana MA, Knaul F. Comprehensive reform to improve health system performance in Mexico. The Lancet. 2006; 368: 1524-34.

[10] World Health Organization. Africa Public Health Alliance \& 15\% + Campaign. (2010) Available online at:

$<$ http://www.who.int/workforcealliance/members_partners/membe r_list/aphra/en/index.html> . Last Accessed 19 May 20112.

[11] Canadian International Development Agency (CIDA). Selective bibliography on basic human needs. CIDA's International Development Information Centre. 1995.

[12] Ekman B., Community-Based Health Insurance In Low-Income Countries: A Systematic Review Of The Evidence. Health Policy and Planning; 2004. 19(5): 249-270.

[13] Braun B, Kim J, Anderson E. Family health and financial literacyforging the connection. Journal of Family and Consumer Sciences 2009; 101 (3): 51-55.
[14] Organization of African Unity: Abuja declaration on HIV/AIDS tuberculosis and other related infectious diseases. Decision OAU/SPS/Abuja/3 Addis Ababa; 2001.

[15] Sambo L.G, Kirigia J.M, Ki-Zerbo, G. BMC Proceedings 2011, 5(Suppl 5):S2 Online available at

<http://www.biomedcentral.com/1753-6561/5/S5/S2> Accessed $5^{\text {th }}$ May,2013.

[16] World Health Organization (WHO): World Health Statistics 2010. Geneva; 2010.

[17] Masiye., F. Investigating health system performance: An application of data envelopment analysis to Zambian hospitals. BMC Health Services Research 2007, 7:58.

[18] Akazili, J., Adjuik, M., Chatio, S., Kanyomse, E., Hodgson, A., Aikins, M., Gyapong, J. What are the Technical and Allocative Efficiencies of Public Health Centres in Ghana? Ghana Medical Journal. 2008; 42(4): 149-155.

[19] McPake, B.,A. D. Asiimwe, F.Mwesigye, et. al. "Informal Economic Activities of Public Health Workers in Uganda: Implications for Quality and Accessibility of Care." Social Science and Medicine. 1999; 49: 849-865.

[20] Harmonization of Health for Africa (HHA): Investing in health for Africa: The African investment case. Brazzaville: HHA; 2010.

[21] High-Level Task Force (HLTF) on Innovative Finance for Health Systems: Working Group 1 Report: Constraints to scaling up and costs. Geneva: International Health Partnership +; 2008.

[22] World Bank. World Development Indicators. 2010. Available at: http://data.worldbank.org/data-catalog/world-developmentindicators, Accessed $23^{\text {rd }}$ March 2012.

[23] The Business of Health in Africa: Partnering with the Private Sector to Improve People's Lives. Washington, DC: International Finance Corporation; 2007.

[24] World Bank.1999. Voices of the poor: can anyone hear us? Vol.1. Washington, DC: World Bank.

[25] World Bank. 2000. World Development Report 2000/2001: Attacking poverty. Washington, DC: World Bank.

[26] WHO. 2000. The World Health Report 2000 Health Systems: Improving performance. Geneva: World Health Organization.

[27] Adeyemo, DLocal Government and Health care delivery in Nigeria: A case study ,J. Hum. Ecol., 2005. 18(2): 149-160.

[28] Soafer, S., Firminger, K.,.Patient's perception of the quality of health services. Annu Rev Public Health. 2005;26:513-59.

[29] Sule, S. et al.,2008. Utilization of primary health care facilities: lessons from a rural community in southwest Nigeria. Niger $J$ Med. ;17(1):98-106.

[30] Mwabu G. Financing health services in Africa: An assessment of alternative approaches. Working Paper Series 0457. Washington, DC: World Bank. 1990.

[31] World Bank. Financing health services in developing countries: An agenda for reform. Policy Study PUB-6563. Washington, DC: World Bank. 1987.

[32] World Bank. Innovations in health care financing. Proceedings from a World Bank Conference, March 10-11. Washington, DC: World Bank. 1997.

[33] Ranson M. Reduction of catastrophic health care expenditures by a community-based health insurance scheme in Gujarat, India: current experiences and challenges. Bulletin of the World Health Organization, 2002; 80: 613-21.

[34] Xu K, Evans D, Carrin G et al. Protecting households from catastrophic health spending. Health Affairs (Millwood). 2007; 26: 972-83.

[35] Robert B, Kuganab Lem. A Content Analysis of the Ghana National Health Insurance Scheme. Health Policy and Development Journal . 2009; 7(1):23-34.

[36] 36. Bennett S. The role of community-based health insurance within the health care financing system: a framework for analysis. Health Policy and Planning. 2004; 19: 147-58.

[37] Penaluna, J. 2013 Budget Analysis: Healthcare expenditure, NHI \& Corruption. What's in store for South Africa this year. Accessed $11^{\text {th }}$ June, 2013.

[38] Arodiogbu L. Introducing Social Health Insurance to Solve problems of poor health Sector in Nigeria. MA Thesis. University of Leeds. 2005.

[39] WHO (2000) Health Systems: Improving Performance. The World Health Report 2000.WHO, Geneva.

[40] WHO. 2001. Report of the Commission on Macroeconomics and Health. Geneva: World Health Organization. 
[41] Dror D, Preker A. Social reinsurance: a new approach to sustainable community health financing. Washington, DC/Geneva: 2002. The World Bank/International Labour Organization.

[42] Carrin G., Waelkens M., Criel, B. Community-based health insurance in developing countries: a study of its contribution to the performance of health financing systems. Tropical Medicine and International Health. 2005; 10:8; 799-81.

[43] van Ginneken W. Social security for the informal sector: a new challenge for the developing countries. International Social Security Review.1999;52, 49-69.

[44] Ekman., B. Community-based health insurance in low-income countries: a systematic review of the evidence. Health Policy and Planning.2004;19, 249-270.

[45] Preker, A.S., Carrin, G., Dror, D., et al. Effectiveness of community health financing in meeting the cost of illness. Bulletin of the World Health Organization 2002; 80: 143-50.

[46] International Labour Organization (ILO) 2006. INDIA Yeshasvini Co-Operative Farmers Health Scheme (Karnataka) Available online at

<http://www.ilo.org/public/english/region/asro/bangkok/events/sis /download/paper18.pdf > Accessed $22^{\text {nd }}$ May, 2013.
[47] Baeza C, Montenegro F \& Nun ez M. Extending Social Protection in Health Through Community Based Health Organizations. Evidence and Challenges. International Labour Organization, Geneva. 2002.

[48] Davies,P., Carrin, G. Risk-pooling: necessary but not sufficient. Bulletin of the World Health Organization 2001; 79-587.

[49] WHO, World Health Assembly. Resolution on health research, 2005. Available online at <http://www.who.int/rpc/meetings/58th_WHA_resolution.pdf $>$ Accessed $20^{\text {th }}$ May,2013.

[50] World Health Organization. Guidelines for the Treatment of Malaria: Second Edition. Geneva: WHO, 2010. Accessed $10^{\text {th }}$ June 2011.

[51] Lavis J. Supporting Evidence-Informed Policymaking. $8^{\text {th }}$ Annual Symposium of the International Network Health Policy and Reform, Krakow, Poland. 2009. Accessed 10 ${ }^{\text {th }}$ June, 2012.

[52] Lavis, J.N., Oxman, A.D., Lewin S, et al. Support Tools for evidence-informed health Policymaking (STP). Health Res Policy Syst 2009;7(Suppl 1):I1.

[53] International Labour Organization, ILO/STEP. Methodological guide for undertaking case studies: health micro insurance schemes. Geneva: International Labour Organization. 2000. 